as fast as he could, and reached a solid standing-ground, but not before perceiving that the guide, who walked behind him, had sunk up to the middle in the sand, and indeed soon disappeared. All the slope sank with increasing swiftness, swelling out at the bottom and opening out to give forth a stream of mud of at least ten metres in height, which shot like a wild torrent across the plateau, and precipitated itself towards the Val de Bove. Immediately all the moving sand, to more than thirty metres in height, was diluted and drawn along, as were also the stones and blocks it contained, and which rolled over each other pell-mell. Fortunately they succeeded in extricating the guide, covered with mud, torn and bruised.

Seeking the origin of these eruptions of mud, M. de Saussure observes first that they take place in the neighbourhood of the central cone of Etna, and that they all escape from the foot of the cone and the very isclined slopes which support it. They proceed then exclusively from the water stored in the beds of ashes. These causes seem to account for this mass of water. r. The hot vapours. The cone seems almost exclusively composed of ashes and movable stones, and during the eruption an enormous mass of vapour must have traversed it. There are, moreover, numerous fumeroles in the upper part. These vapours have been condensed, all the more readily that they have encrusted the mantle of snow which envelops the summit of the mountain. 2. The melting of this snow, determined less by the fall of ashes on the surface than by the heat which radiates from the interior and the vapours which traverse the porous mass of the cone. 3. The abundant vapours falling from the cloud of vapours projected by the crater. The two first causes are the most important; the last has most especially given rise to surface streams, the traces of which are apparent. The water gradually collecting in excess in the lower parts of the cone, ends by forming these enormous deposits, which, at a given moment, yielding to their weight, cause an eruption to the outside, turning over and diluting the beds of ashes which oppose its exit.

In a communication to us M. de Saussure gives an analysis of the little mud-heaps which have projected through the snow. They are composed of a grey powder formed of pozzolana (spongy amorphous silicates), white, grey, and black (augite), mixed with $(b)$ amorphous sulphur (yellow and orange coloured); (c) calcium sulphate (hydrated) in numerous well-defined small crystals; (d) sodium and potassium sulphate; $(e)$ calcium and potassium chloride; $(f)$ perchloride of iron and oxychloride of iron; $(g)$ indication of copper salts.

The crystals are all of alabaster, and so wet that they can only have been formed after the eruption of the mud in drying. There is no crystallised silica nor feldspar. The sulphur in the mud is curious to observe. It must have condensed out of the eruptive vapours which formed the water to make the mud by mixing with old ashes under the snow, and by their expansion driven small quantities of that mud through the snow. This mud, when heated, evaporates sulphur, sulphurous and sulphuric acid, some perchloride of iron, and some hydrochloric acid.

\section{THE ACTION OF HEAT IN VACUO ON METALS}

IN the course of my experiments on electric lighting I have developed some striking phenomena arising from the heating of metals by flames and by the electric current, especially wires of platinum, and platinum alloyed with iridium. These experiments are in progress.

The first fact observed was that platinum lost weight when heated in a flame of hydrogen, that the metal coloured the flame green, and that these two results continued until the whole of the platinum in contact with the flame had disappeared. A platinum wire four-thousandths of an inch in diameter, and weighing 306 mgrms., was bunched together and suspended in a hydrogen flame. It lost weight at the rate of a fraction less than I mgrm. per hour as long as it was suspended in the flame. When a platinum wire is stretched between two clamping posts, and arranged to pass through a hydrogen flame, it is coloured a light green; but when the temperature of the wire is raised above that of the flame, by passing a current through it, the flame is coloured a deep green. To ascertain the diminution in the weight of a platinum wire when heated by the electric current, I placed between two clamping posts a wire five-thousandths of

x A Faper rcad by Mr. T. A. Edison before the American Association for the Advancement of Science; Saratoga Meeting. an inch in diameter, and weighing $266 \mathrm{mgrms}$. This wire, after it was brought to incandescence for twenty minutes by the current, lost I mgrm. The same wire was then raised to incandescence; for twenty minutes it gave a loss of 3 mgrms. Afterwards it was kept incandescent for one hour and ten minutes, at which time it weighed $258 \mathrm{mgrms}$. - a total loss of $8 \mathrm{mgrms}$. Another wire, weighing $343 \mathrm{mgrms}$., was lept moderately incandescent for nine consecutive hours, after which it weighed $301 \mathrm{mgrms}$, showing a total loss of 42 mgrms. A platinum wire twentythousandths of an inch in diameter was wound in the form of a spiral one-eighth of an inch in diameter and one-half an inch in length. The two ends of the spiral were secured to clamping posts, and the whole apparatus was covered with a glass shade $2 \frac{1}{2}$ inches in diameter and 3 inches high. Upon bringing the spiral to incandescence for twenty minutes that part of the globe in line with the sides of the spiral became slightly darkened; in five hours the deposit became so thick that the incandescent spiral could not be seen through the deposit. This film, which was most perfect, consisted of platinum, and I have no doubt but that large plates of glass might be coated economically by placing them on each side of a large sheet of platinum, kept incandescent by the electric current. This loss. in weight, together with the deposit upon the glass, presented a very serious obstacle to the use of metallic wires for giving light by incandescence, but this was easily surmounted after the cause was ascertained. I coated the wire forming the spiral with the oxide of magnesium, by dusting upon it finely powdered acetate of magnesium: while incandescent the salt was decomposed by the heat, and there remained a strongly adherent coating of the oxide. This spiral so conted was covered with a glass shade, and brought to incandescence for several minutes ; but instead of a deposit of platinum upon the glass, there was a deposit of the oxide of magnesia. From this and other experiments I became convinced that this effect was due to the washing action of the air upon the spiral; that the loss of weight in and the coloration of the hydrogen flame were also due to the wearing away of the surface of the platina to the attrition produced by the impact of the stream of gases upon the highly incandescent surface, and not to volatilisation, as commonly understood; and I venture to say, although I have not tried the experiment, that metallic sodium cannot be volatilised in high vacua by the heat derived from incandescent platinum; any effect that may be produced will be due to the washing action of the residual air. After the experiment last described I placed a spiral of platinum in the receiver of a common air-pump, and arranged it in such a manner that the current could pass through it, while the receiver was exhausted. At a pressure of 2 millimetres the spiral was kept at incandescence for two hours before the deposit was sufficient to become visible. In another experiment, at a higher exhaustion, it required five hours before a deposit became visible. In a sealed glass bulb, exhausted by a Sprengel pump to a point where a quarter of an inch spark from an induction-coil would not pass between points $\mathrm{I}$ millimetre apart, was placed a spiral, the connecting wires passing through the glass. This spiral has been kept at the most dazzling incandescence for hours without the slightest deposit becoming visible.

I will now describe other and far more important phenomena observed in my experiments. If a short length of platinum wir. one-thousandth of an inch in diameter be held in the flame of a Bunsen burner, at some part it will fuse, and a piece of the wire will be bent at an angle by the action of the globule of melted platinum; in some cases there are several globules formed simultaneously, and the wire assumes a zigzag shape. With a wire four-thousandths of an inch in diameter this effect does not take place, as the temperature cannot be raised to equal that of the smaller wire, owing to the increased radiating surface and mass. After heating if the wire be examined under a microscope, that part of the surface which has been incandescent will be found covered with innumerable cracks. If the wire be placed between clamping posts, and heated to incandescence for twenty minutes, by the passage of an electric current, the cracks will-be so enlarged as to be seen with the naked eye; the wire, under the microscope, presents a shrunken appearance, and is full of deep cracks. If the current is continued for several hours these effects will so increase that the wire will fall to pieces. This disintegration has been noticed in platina long subjected to the action of a flame by Prof. John W. Draper. The failure of the process of lighting invented by the French chemist Tessie du Motay, who raised sheets of platinum to incandescence by 
introducing them into a hydrogen flame, was due to the rapid disintegration of the metal. I have ascertained the cause of disintegration of the metal. this phenomenon, and ho have produced a metal in a state produces it, and in and which is absolutely stable at a temperature where nearly all substances melt or are consumed; a metal which, although originally soft and pliable, becomes as homowhich, although ord as rigid as steel. When wound in the form geneous as glass and as rigid as steel. When at the most dazzling incandescence as when cold, and cannat be annealed by any process now commonly known, for the cause of this shrinking process now cracking of the wire is due entirely to the expansion of the air in the mechanical and physical pores of the platinum, and the contraction upon the escape of the air. Platinum as sold in commerce may be compared to sandstone, in which the whole is made of a great number of particles with many air spaces. The sandstone upon melting becomes homogeneous and no air spaces exist.

With platinum or any metal the air spaces may be eliminated and the metal made homogeneous by a very simple process. This process I will now describe. I had made a large number of platinum spirals, all of the same size and from the same quality of wire ; each spiral presented to the air a radiating sirface of three-sixteenths of an inch ; five of these were brought by the electric current up to the melting-point, the light was measured by a photometer, and the average light was equal to four standard candles for each spiral just at the melting-point. One of the same kind of spirals was placed in the receiver of an air-pump, and the air exhausted to 2 millimetres; a weak current was then passed through the wire, to slightly warm it for the purpose of assisting the passage of the air from the pores of the metal into the vacuum. The temperature of the wire was gradually angmented, at intervals of ten minutes, until it became red. The object of slowly increasing the temperature was to allow the air to pass out gradually and not explosively. Afterward the current was increased at intervals of fifteen minutes. Before each increase in the current the wire was allowed to cool, and the contraction and expansion at these high temperatures caused the wire to weld together at the points previously containing air. In one hour and forty minutes this spiral had reached such a temperature without melting that it was giving a light of twentyfive standard candles, whereas it would undoubtedly have melted before it gave a light of five candles had it not been put through the above process. Several more spirals were afterwards tried, with the same result. One spiral, which had been brought to these high temperatures more slowly, gave a light equal to thirty siandard candles. In the open air this spiral gave nearly the same light, although it required more current to keep it at the same temperature. Upon examination of these spirals, which had passed through the vacuum process, by the aid of a microsrove no cracks were visible; the wire had become as white as siver, and had a polish which could not be given it by any other means. The wire had a less diameter than before treatment, and it was exceedingly difficult to melt in the oxy-hydrogen flame. As compared with untreated platinum, it was found that it was as hard as the steel wire used in pianos, and that it could not be anciealed at any temperature.

My experiments with many metals treated by this process b-ve proved to my satisfaction, and I have no hesitation in stating that what is known as annealing of metals to make them soft and pliable is nothing more than the cracking of the metal. In every case where a hard drawn wire had been annealed a powerful microscope revealed myriads of cracks in the metal. Since the experiments of which I have just spoken I have, by the aid of Sprengel mercury pumps, produced higher exhaustion, and have, by consuming five hours in excluding the air from the wire and intermitting the current a great number of times, succeeded in obtaining a light of eight standard candles from a spiral of wire with a total radiating surface of I-32nd of an inch, or a surface ¿bout equal to one grain of buckwheat. With spirals of this small size which have not passed through the process, the average amount of light given out before melting is less than one standard candle. Thus I am enabled, by the increased capacity of platinum, to withstand high temperatures, to employ small radiating surfaces, and and thus reduce the energy required for candle light. I can now obtain eight separate jets, each giving out an absolutely steady light, and each equal to sixteen standard candles, or a total of I 28 candles, by the expenditure of 30,000 foot-pounds of energy, or less than one horse-power. As a matter of curiosity I have made spirals of other metals, and excluded the air from them in the manner stated. Common iron wire may be made to give a light greater than platinum not heated. The iron becomes as hard as steel, and just as elastic. Nickel is far more refractory than iron. Steel wire used in pianos becomes decarbonised, but remains hard, and becomes the colour of silver. Aluminium melts only at a whit $\epsilon$-heat.

In conclusion, it may be interesting to state that the meltingpoints of many oxides is dependent on the manner of applying the heat ; for instance, pure oxide of zirconium does not fuse in the flame of the oxy-hydrogen blow-pipe, while it melts like wax and conducts electricity when on an incandescent platinum spiral which is at a far lower temperature; on the other hand oxide of aluminum easily melts in the oxy.hydrogen flame, while it only vitrifies on the platinum spiral.

\section{THE INAUGURATION OF ARAGO'S STATUE}

THE statue to Arago recently unveiled at Perpignan is not the first erected to that great astronomer and greater physicist. In $1867 \mathrm{M}$. Isaac Pereire, then representative of the native place of Arago in the Imperial Chamber of Deputies, erected one at his own expense at Estagel. The inauguration was accompanied by speeches delivered by the generous donor, M. Bertrand, the perpetual secretary of the Academy of Science, and others. It was stated then that Arago had supported against his own party the construction of the railways by public companies, and had been grossly abused by some of his political friends. Although a political leader, it must be said, to the glory of Arago, that he never was influenced by party considerations. $\mathrm{He}$ was always writing, and speaking, and voting according to the dictamina of his own judgment. These facts should be remembered, as efforts have been made in the recent Arago celebration, to degrade him into a mere politician, which never was the case. Arago was made a member of the Provisiona? Government of France in February, 1848; it was owing to his personal exertion that the abolition decree was proclaimed before the convocation of the National Assembly. It is true that he was appointed in the beginning of May one of the quinquemuirs of the Executive Commission. But this Government was overthrown by the popular rising of the end of June, and frors: that time he abstained from taking any prominent part is politics.

Arago was not rich, his works having been inostiy published in the Annuaire du Bureau des Longitudes without any copyright, and sold for the benefit of the Bureau, of which he was the mosit influential member. His paying works were all of them posthumous, and edited by $M$. Barras, the Perpetual Secretary of the Agricultural Society of France. The sale was not so large as anticipated, and the publisher who purchased the copyright from the inheritors failed. The sale of the Annuaire was so large during Arago's lifetime, that the Burean had a profit by it. Since his death it has become necessary to provide special functs for the publication of that useful work.

Arago had no salary at all as director of the Observatory. I?e was appointed every year by the Bureau, receiving only 200 . for his membership. His other salaries were $50 l$. as a member of the Academy of Sciences, 250 . as Perpetual Secretary, and when he was lecturing on astronomy $50 \%$. The functions of deputy and member of Municipal Council of Paris being entirely gratuitous, he was no receiver of any other public moneys. Under the Republic his membership of the Assembly brought him $\mathrm{I} l$. a day.

From the eloquent eloge pronounced by M. Paul Bert at the recent inauguration, we take the following extract :-

"To contemplate Arago under all the aspects that may attract the admiration of posterity we must think of him as a man of science overturning the Newtonian hypothesis of the emission of Iight, determining the physical constitution of the sun, explaining the scintillation of the stars, the nature of the aurora borealis, discovering magnetisation by currents, the origin of the electric telegraph, extending to all bodies magnetic properties; finally, for I must limit myself to the most prominent points, indicating to the most eminent of his disciples the star still unknown and invisible, whose discovery introduced order among the perturbed planets, and which still remains the most extraordinary mark of the power of human genius. As a professor, again, before three thousand auditors at the Observatory, or in his chair as Perpetual Secretary writing his incomparable scientific notices, or dictating, when blind, his popular astronomy, always, by speech or by pen, marvellous for his clearncse, his 